\title{
Employment and Output Effects of Federal Regulations on Small Business
}

\author{
Dustin Chambers* \\ Salisbury University \\ and \\ Jang-Ting Guo ${ }^{\dagger}$ \\ University of California, Riverside
}

September 13, 2018

\begin{abstract}
This paper examines the disparate impact of US federal regulations on small businesses. In the context of a two-sector dynamic general equilibrium macroeconomic model, we obtain three empirically testable implications of higher regulation: 1) the total number of small firms is reduced, 2) the employment share of small firms shrinks, and 3) small firms' share of total output declines. Since the first of these testable hypotheses has already been confirmed in previous studies, we focus our attention on the latter two, and find strong empirical support for both. Specifically, we estimate that a ten percent increase in federal regulations reduces the employment share of small firms by nearly $0.7 \%$, and an equally large increase in federal regulations decreases the output share of small firms by nearly $1.5 \%$.
\end{abstract}

JEL Classification: C23, E23, L11, L51

Keywords: regulation, small business, firm size, industry concentration, dynamic general equilibrium.

\footnotetext{
* Corresponding Author. Department of Economics and Finance, Salisbury University, 1101 Camden Ave., Salisbury, MD 21801, 1-410-543-6320, Fax: 1-410-546-6208, E-mail: DLChambers@salisbury.edu.

${ }^{\dagger}$ Department of Economics, 4123 Sproul Hall, University of California, Riverside, CA, 92521, 1-951-8271588, Fax: 1-951-827-5685, E-mail: guojt@ucr.edu.
} 


\section{Introduction}

It is well known that tracing the economic impact of federal regulations on households and firms is a difficult and contentious task. Well-designed regulations may enhance social welfare by reducing negative externalities and correcting market failures, while poorly conceived regulations ("red tape") may yield few if any benefits. Nonetheless, business regulations impose additional compliance costs on firms. For example, Dawson and Seater (2013) report that between 1949 and 2011, federal regulations resulted in an accumulated loss of goods and services totaling $\$ 38.8$ trillion. More worryingly, there is strong reason to suspect that these high costs disproportionately burden smaller firms. In another recent study, Crain and Crain (2014) estimate that small businesses (with fewer than 50 employees) faced average compliance costs of $\$ 11,724$ per employee as compared to $\$ 9,083$ for large businesses (with more than 100 employees). Given the importance of small business as a source of economic dynamism, innovation, job growth and social mobility, it is surprising that few studies have investigated the outsized impact of regulations on these critically important businesses. Moreover, the previous research that has examined this topic is primarily empirical, and does not postulate formal theoretical models to motivate its regression models or results. Therefore, our paper seeks to fill this gap in the literature with a two-sector general equilibrium model that generates empirically testable predictions regarding the disparate impact of federal regulations on small and large firms. Consistent with our model, this paper presents empirical evidence that higher regulations reduce both small firms' share of employment and output within the U.S. economy.

Although it has been long understood that economies of scales in regulatory compliance costs may give larger firms an advantage over their smaller competitors, a lack of industry-specific regulation data has hampered the empirical examination of this topic. Early research either relied on crude proxies for the level of federal regulation like page counts in the Code of Federal Regulations (CFR) (see for example Dawson and Seater [2013]) or as noted by Kitching et al. (2015), potentially biased feedback from surveys sent to small business owners. Fortunately, we can empirically test the effects of regulations on small businesses by utilizing a relatively new database called RegData, which was constructed using machine learning algorithms that mined the CFR for 
language consistent with regulations and probabilistically matched these regulations to the NAICS-coded industries to which they most likely apply (see McLaughlin and Sherouse [2017] for details). Indeed, several recent studies have used RegData to examine the general impact of federal regulations on entrepreneurship, with conflicting results. Bailey and Thomas (2017) find that greater industry-specific regulations are associated with a reduction in the entry of new firms, with the greatest impact affecting smaller firms. Similarly, Chambers et al. (2018) find that an increase in industry-specific regulations is associated with a reduction in both the number and employment of small firms, whereas large firms (with 500 or more employees) are unaffected. In a notable departure from the above two papers, Goldschlag and Tabarrok (2018) modify their dependent variables (new firm formation and hiring) by way of the Davis-HaltiwangerSchuh (DHS) transformation, which is claimed to be a more robust measure of dynamism. ${ }^{1}$ The resulting regression models, despite utilizing a right-hand-side structure very similar to Bailey and Thomas (2017) and Chambers et al. (2018) and the same underlying data sources (i.e., RegData and the Census of US Business), fail to find a statistically significant association between federal regulations and the transformed measures of new firm formation or hiring. This lack of consensus, which clearly results from differences in the regression models' dependent variables, underscores the need for a theory to generate testable empirical hypotheses, which in turn provide guidance for appropriate empirical specifications.

The analytical framework that forms the basis for our empirical work is Dhawan and Guo's (2001) dynamic general equilibrium macroeconomic model with two production sectors which are made up of large and small firms, respectively. The two sectors differ from each other with regard to the level of fixed set-up costs and returns-toscale in their production functions. Each sector has an intermediate-good segment in which monopolistically competitive firms operate with fully mobile capital and labor inputs. The number of these intermediate firms is determined endogenously through the condition of free entry and exit. A final good is produced in each sector from the set of available intermediate goods in a perfectly competitive environment. These two final goods are then aggregated into a single output (GDP) that can be consumed or invested

\footnotetext{
${ }^{1}$ For more details on the DHS transformation, see Davis et al. (1998).
} 
by the representative household. This parsimonious structure is motivated by the observation that both large and small firms exist side by side within many industries, while practically producing the same commodity.

In a calibrated version of the above macroeconomy, Dhawan and Guo (2001) numerically show that at the model's steady state, an increase in government regulations will yield the following empirically testable outcomes: 1) the total number of small firms is reduced, 2) the employment share of small firms shrinks, and 3) small firms' share of total output declines. The first outcome is appropriately tested and supported by Bailey and Thomas (2017) and Chambers et al. (2018), but the latter two predictions have not been empirically evaluated in the literature. Therefore, our empirical analysis tests for a reduction in both small firms' share of employment and output in response to higher federal regulations. With regard to both predictions, we find strong evidence in favor of our theoretical model. Specifically, we find that a ten percent increase in federal regulations reduces the employment share of small firms by nearly $0.7 \%$, and that an equally large increase in federal regulations decreases the output share of small firms by nearly $1.5 \%$.

The remainder of this paper is organized as follows. Section 2 presents the model economy and analyzes its equilibrium conditions. Section 3 describes our empirical models and discusses their results. Section 4 concludes.

\section{The Model}

This section sketches the two-sector dynamic general equilibrium macroeconomic model developed by Dhawan and Guo (2001). The economy is inhabited by a unit measure of identical infinitely-lived households, together with two types of heterogeneous firms under increasing returns and monopolistic competition. In particular, large and small firms produce the same final good using technologies that exhibit identical factor intensities, but subjected to different fixed set-up costs and returns-to-scale in production.

\subsection{Firms}

The macroeconomy's production side is comprised of two sectors indexed by $i=1,2$, where sector 1 is populated by large firms and sector 2 consists of small firms. Since firms are solving a static profit maximization problem, the time-subscripts will be 
suppressed for notational convenience in this subsection. The final good in each sector $Y_{i}$ is produced from combining a continuum of intermediate inputs $X_{i j}, j \in\left[0, M_{i}\right]$, with the following constant returns-to-scale technology: $Y_{i}=\left[\int_{0}^{M_{i}} X_{i j}^{\lambda} d j\right]^{\frac{1}{\lambda}}, 0<\lambda<1$, where $M_{i}$ represents the endogenously determined measure of intermediate inputs that are utilized in sector i. The final-good segment of each sector is assumed to be perfectly competitive, and we denote $\mathrm{P}_{\mathrm{ij}}$ as the price of the $\mathrm{j}$ 'th intermediate input relative to the final good in sector i. The final-good producers' profit maximization condition yields the demand function: $X_{i j}=\left(P_{i j}\right)^{\frac{1}{\lambda-1}} Y_{i}$, where the price elasticity of demand is $\frac{1}{1-\lambda}$. This in turn implies that $\frac{1}{\lambda}>1$ is equal to the markup ratio of price over marginal cost or the degree of monopoly power.

Each intermediate good is produced by a monopolist, who implements a production function that allows for increasing returns-to scale:

$$
X_{i j}=\left(K_{i j}^{\alpha} L_{i j}^{1-\alpha}\right)^{\gamma_{i}}-Z_{i}, 0<\alpha<1, \gamma_{i} \geq 1, Z_{i}>0,
$$

where $\mathrm{K}_{\mathrm{ij}}$ and $\mathrm{L}_{\mathrm{ij}}$ are capital and labor inputs employed by the $\mathrm{j}$ 'th intermediate producer in sector i. In addition, $Z_{\mathrm{i}}$ represents a constant amount of intermediate goods that must be expended in sector $i$ as fixed costs for setting up production facilities before any sale is made. The presence of such costs implies that the intermediate-good technology (3) exhibits increasing returns in production. Next, in accordance with empirical findings, reported by Mills and Schumann's (1985) and Feigenbaum and Karnani (1991), that small/large firms are more/less flexible in handling market fluctuations since they rely more on variable/fixed factors of production, we postulate that $Z_{1}>Z_{2}$. On the other hand, additional increasing returns-to-scale will be present in (3) when $\gamma_{i}>1$ because of rising marginal productivity. We also note that from a large sample of publicly traded U.S. firms, Dhawan (1996) finds that the degree of returns-to-scale in production is higher for large firms; therefore $\gamma_{1}>\gamma_{2}$ is imposed.

Under the assumption that factor markets are perfectly competitive within each sector, the first-order conditions for intermediate firm j's profit maximization problem are given by 


$$
\mathrm{w}_{\mathrm{i}}=\frac{(1-\alpha) \lambda \gamma_{\mathrm{i}}\left(\mathrm{X}_{\mathrm{ij}}+\mathrm{Z}_{\mathrm{i}}\right) \mathrm{P}_{\mathrm{ij}}}{\mathrm{L}_{\mathrm{ij}}} \text { and } \mathrm{r}_{\mathrm{i}}=\frac{\alpha \lambda \gamma_{\mathrm{i}}\left(\mathrm{X}_{\mathrm{ij}}+\mathrm{Z}_{\mathrm{i}}\right) \mathrm{P}_{\mathrm{ij}}}{\mathrm{K}_{\mathrm{ij}}} \text {, }
$$

where $\mathrm{w}_{\mathrm{i}}$ is the real wage rate and $\mathrm{r}_{\mathrm{i}}$ be the real rental rate of capital in sector $\mathrm{i}$. For analytical simplicity, we further postulate that (i) both capital and labor inputs are fully mobile across the two production sectors; and that (ii) firms can enter and exit the intermediate-good segment of each sector freely, hence they will not make any profit. Using this zero-profit condition and equation (2) yields the equilibrium size of intermediate firm $\mathrm{j}: \mathrm{X}_{\mathrm{ij}}=\frac{\lambda \gamma_{\mathrm{i}}}{1-\lambda \gamma_{\mathrm{i}}} \mathrm{Z}_{\mathrm{i}}$, where $0<\lambda \gamma_{\mathrm{i}}<1$. In what follows, our analysis is restricted to a symmetric equilibrium at which all intermediate-good produces make the same decisions within each sector:

$P_{i j}=P_{i}, X_{i j}=X_{i}, K_{i j}=\frac{K_{i}}{M_{i}}$, and $L_{i j}=\frac{L_{i}}{M_{i}}$, for all $j \in\left[0, M_{i}\right]$, where $K_{i}$ and $L_{i}$ represent the total capital stock and labor hours employed in sector i. It is then straightforward to show that the equilibrium number of intermediate firms in sector $i$ is

$$
M_{i}=K_{i}^{\alpha} L_{i}^{1-\alpha}\left(\frac{1-\lambda \gamma_{i}}{Z_{i}}\right)^{\frac{1}{\gamma_{i}}},
$$

where $\mathrm{M} \equiv \mathrm{M}_{1}+\mathrm{M}_{2}$; and that the sectoral production function for the final good is

$$
\mathrm{Y}_{\mathrm{i}}=\mathrm{M}_{\mathrm{i}}^{\frac{1}{\lambda}} \mathrm{X}_{\mathrm{i}}=\mathrm{A}_{\mathrm{i}} \mathrm{K}_{\mathrm{i}}^{\frac{\alpha}{\lambda}} \mathrm{L}_{\mathrm{i}}^{\frac{1-\alpha}{\lambda}} \text {, where } \mathrm{A}_{\mathrm{i}}=\lambda \gamma_{\mathrm{i}}\left(\frac{1-\lambda \gamma_{\mathrm{i}}}{\mathrm{Z}_{\mathrm{i}}}\right)^{\frac{1-\lambda \gamma_{\mathrm{i}}}{\lambda \gamma_{\mathrm{i}}}} \text {. }
$$

Finally, the total output (GDP) for the economy Y is generated through the following CES aggregator function:

$$
\mathrm{Y}=\left[\phi_{1} Y_{1}^{\rho}+\phi_{2} Y_{2}^{\rho}\right]^{\frac{1}{\rho}}, \phi_{1}, \phi_{2}>0 \text { and }-\infty<\rho<1,
$$

where the elasticity of substitution between $Y_{1}$ and $Y_{2}$ is $\frac{1}{1-\rho} \cdot{ }^{2}$ It follows that the

\footnotetext{
${ }^{2}$ When $\rho=1$, GDP is simply the sum of sectoral outputs, i.e. $Y=Y_{1}+Y_{2}$. In this case, there exists a generic corner solution in which only large firms will produce. This possibility is ruled out since it is not consistent with the empirical evidence.
} 
shadow price of $Y_{i}$ relative to the aggregate output $Y$ is given by $\operatorname{SP}_{i}=\frac{\partial Y}{\partial Y_{i}}=\phi_{i}\left(\frac{Y}{Y_{i}}\right)^{1-\rho}$; and that $\mathrm{Y}=\mathrm{SP}_{1} * \mathrm{Y}_{1}+\mathrm{SP}_{2} * \mathrm{Y}_{2}$ because (5) displays constant returns-to-scale. Under the assumption of full factor mobility, wage and rental rates will be equalized across the two sectors: $\mathrm{SP}_{1} * \mathrm{w}_{1}=\mathrm{SP}_{2} * \mathrm{w}_{2}=\mathrm{w}$ and $\mathrm{SP}_{1} * \mathrm{r}_{1}=\mathrm{SP}_{2} * \mathrm{r}_{2}=\mathrm{r}$.

\subsection{Households}

The economy is also populated by a unit measure of identical infinitely-lived households, each endowed with one unit of time, and maximizes a discounted sum of lifetime utility

$$
\sum_{\mathrm{t}=0}^{\infty} \beta^{\mathrm{t}}\left[\log \mathrm{C}_{\mathrm{t}}-\mathrm{B} \frac{\mathrm{L}_{\mathrm{t}}^{1+\chi}}{1+\chi}\right], 0<\beta<1, \mathrm{~B}>0
$$

where $\beta$ is the discount factor, $\mathrm{B}$ is a preference parameter, and $\chi$ denotes the inverse of the intertemporal elasticity of substitution in labor supply. In addition, $\mathrm{C}_{t}$ and $\mathrm{L}_{t}$ are the representative household's consumption and labor hours at time $t$, respectively. The budget constraint that it faces is given by

$$
\mathrm{C}_{\mathrm{t}}+\mathrm{K}_{\mathrm{t}+1}-(1-\delta) \mathrm{K}_{\mathrm{t}}=\mathrm{w}_{\mathrm{t}} \mathrm{L}_{\mathrm{t}}+\mathrm{r}_{\mathrm{t}} \mathrm{K}_{\mathrm{t}}, \mathrm{K}_{0}>0 \text { given, }
$$

where $\mathrm{K}_{\mathrm{t}}$ is the household's capital stock, and $\delta \in(0,1)$ denotes the capital depreciation rate. The first-order conditions for the household's dynamic optimization problem are

$$
\begin{aligned}
& \mathrm{BC}_{t} \mathrm{~L}_{t}^{\chi}=w_{t}, \\
& \frac{1}{C_{t}}=\frac{\beta}{C_{t+1}}\left[1-\delta+r_{t+1}\right], \\
& \lim _{t \rightarrow \infty} \beta^{t} \frac{K_{t+1}}{C_{t}}=0,
\end{aligned}
$$

where (8) is an intra-temporal condition that equates the household's marginal rate of substitution between consumption and leisure to the real wage rate; equation (9) is the standard Euler equation for intertemporal consumption choices; and (10) is the transversality condition.

\subsection{Symmetric Equilibrium and Steady State}

We focus on the model's symmetric equilibrium in which producers of final and intermediate goods maximize profits; households maximize utilities; and the marketclearing conditions in capital and labor markets will hold: 
$\mathrm{K}_{\mathrm{t}}=\mathrm{K}_{1 \mathrm{t}}+\mathrm{K}_{2 \mathrm{t}}$, and $\mathrm{L}_{\mathrm{t}}=\mathrm{L}_{1 \mathrm{t}}+\mathrm{L}_{2 \mathrm{t}}$. It can be shown that the equilibrium fractions of aggregate capital stock and labor hours used in sector 1 , denoted as $\mu_{\mathrm{Kt}}$ and $\mu_{\mathrm{Lt}}$, are equal to the same constant for all $t$,

$$
\mu_{\mathrm{Kt}}=\mu_{\mathrm{Lt}}=\frac{\eta^{\frac{\lambda}{1-\lambda}}}{1+\eta^{\frac{\lambda}{1-\lambda}}} \equiv \mu \text {, where } \eta=\frac{\gamma_{2}}{\gamma_{1}}\left(\frac{Z_{1}}{1-\lambda \gamma_{1}}\right)^{\frac{1-\lambda \gamma_{1}}{\lambda \gamma_{1}}}\left(\frac{1-\lambda \gamma_{2}}{Z_{2}}\right)^{\frac{1-\lambda \gamma_{2}}{\lambda \gamma_{2}}} \text {. }
$$

Substituting (11) into (4) and (5) yields that the total output of the economy is given by

$$
\mathrm{Y}_{\mathrm{t}}=\mathrm{AK}_{\mathrm{t}}^{\frac{\alpha}{\lambda}} \frac{1-\alpha}{\mathrm{t}}^{\frac{1-\alpha}{\lambda}} \text {, where } \mathrm{A}=\left\{\phi_{1}\left[\mathrm{~A}_{1} \mu^{\frac{1}{\lambda}}\right]^{\rho}+\phi_{2}\left[\mathrm{~A}_{2}(1-\mu)^{\frac{1}{\lambda}}\right]^{\rho}\right\}^{\frac{1}{\rho}} \text {, }
$$

where $\alpha<\lambda$ to rule out the possibility of sustained endogenous growth.

Next, using the model's equilibrium conditions, it is straightforward to show that there exists a unique interior steady state at which the real rental rate, hours worked, and capital stock (expressed as bar variables) are

$$
\overline{\mathrm{r}}=\frac{1}{\beta}-(1-\delta), \quad \overline{\mathrm{L}}=\left[\frac{(1-\alpha) \overline{\mathrm{r}}}{\mathrm{B}(\overline{\mathrm{r}}-\alpha \delta)}\right]^{\frac{1}{1+\chi}}, \quad \text { and } \quad \overline{\mathrm{K}}=\left(\frac{\overline{\mathrm{r}}}{\alpha \mathrm{A}}\right)^{\frac{\lambda}{\alpha-\lambda}} \overline{\mathrm{L}}^{\frac{1-\alpha}{\lambda-\alpha}} \text {. }
$$

With equation (13), the corresponding steady-state expressions of all remaining endogenous variables can be easily derived.

\section{Empirical Results}

In a calibrated version of the above macroeconomy, Dhawan and Guo (2001; Table 3, Experiment \#2, p. 659) numerically show that increased government regulations, represented by lowering the markup-ratio parameter $\lambda$, will result in three empirically testable outcomes on the model's steady state: 1) the total number of small firms $\overline{\mathrm{M}}_{2}$ falls; 2) the employment share of small firms $\frac{\overline{\mathrm{L}}_{2}}{\overline{\mathrm{L}}}$ shrinks; and 3) the output share of small firms $\frac{\overline{\mathrm{SP}}_{2} * \overline{\mathrm{Y}}_{2}}{\overline{\mathrm{Y}}}$ declines. Intuitively, a higher level of monopoly power decreases the individual size and total number of small firms $\left(\mathrm{X}_{2}\right.$ and $\left.\mathrm{M}_{2}\right)$. As a result, the employment as well as the output shares of small firms will fall. 
As it turns out, the first empirical outcome has already been confirmed by Bailey and Thomas (2017) and Chambers et al. (2018). Using a panel of firm births and deaths at the 4-digit NAICS industry level from the Census of US Business (SUSB) and industry-level federal regulation data from RegData, Bailey and Thomas (2017) find robust evidence that higher federal regulations within a given industry reduces the overall number of small firms within that industry. Specifically, a one percent increase in federal regulations is associated with $0.047 \%$ reduction in small firm formation (i.e. births) in the subsequent year. Utilizing a similar panel of net annual changes in total small firms by industry derived from the SUSB database matched with changes in industry-level federal regulations from RegData, Chambers et al. (2018) find robust evidence that a one percent increase in federal regulations is associated with a contemporaneous $0.042 \%$ decline in total small firms. Despite modeling differences, both papers yield nearly identical results: a $10 \%$ increase in federal regulations is associated with a nearly $0.5 \%$ reduction in the number of small firms.

To verify the remaining two testable implications from our dynamic general equilibrium model, the empirical analysis below uses regression models similar to Bailey and Thomas (2017) and Chambers et al. (2018) to test for a reduction in both small firms' share of employment and output in response to higher federal regulations.

\subsection{Employment Share of Small Firms}

To test whether the employment share of small firms shrinks in response to rising regulation, we collect employment estimates by industry and firm size from the Census Bureau's SUSB dataset and match 5-digit NAICS code industries with federal regulations from RegData. ${ }^{3}$ Unlike gross receipts (see Section 3.2), employment estimates are available annually, thus our resulting panel spans 18 time periods (1998-2015) and 248 industries. Using this data, we estimate the fixed effects panel model of Bailey and Thomas (2017), replacing their dependent variable (small firm births and deaths) with the natural $\log$ of the employment share of small firms: ${ }^{4}$

\footnotetext{
${ }^{3}$ Following the US Small Business Administration, we classify firms with 500 or more employees as large businesses and firms with fewer employees as small businesses.

${ }^{4}$ Bailey and Thomas (2017) conduct extensive identification testing which strongly supports this regression model specification - i.e. the log dependent variable regressed on time and industry fixed effects and the $\log$ of regulations, hence we adopt it as our baseline model for testing purposes.
} 


$$
\text { employment }_{\mathrm{it}}=\alpha_{\mathrm{i}}+\delta_{\mathrm{t}}+\beta \cdot \operatorname{reg}_{\mathrm{it}}+\mathrm{u}_{\mathrm{it}} \text {, }
$$

where employment $t_{i t}$ is the natural $\log$ of the share of total industry i's employment by small firms in year $t, \alpha_{\mathrm{i}}$ is the industry fixed effect, $\delta_{\mathrm{t}}$ is a period fixed effect, reg $\mathrm{g}_{\mathrm{it}}$ is the natural $\log$ of total federal regulatory restrictions applicable to industry $i$ in year $t$, and $u_{i t}$ is a mean zero error term. The industry fixed effects capture any differences in average employment shares of small firms across industries; while the period fixed effects capture common shocks to employment shares across industries, including business cycles and changes in government policy (which may be correlated with variation in industry-level regulations). Given the double-log specification of the model, the coefficient on industry regulations can be interpreted as an elasticity measure. Estimates of Equation (14) are provided in Table 1.

In our preferred specification (see column 1 of Table 1), the regulation coefficient is negative and statistically significant at the $1 \%$ level, implying that a one percent increase in federal regulations reduces the employment share of small firms by nearly $0.07 \%$. While this coefficient may seem small in magnitude, it implies that a $10 \%$ increase in federal regulations reduces the employment share of small firms within an affected industry by almost $0.7 \%$. Given that nearly 59 million workers were employed by U.S. small businesses in 2015 , the volume of affected workers is quite large. ${ }^{5}$ Overall, the goodness of fit of this model is quite high, explaining just over $96 \%$ of the variation in the employment share of small firms. To demonstrate the robustness of these results, columns 2 through 4 of Table 1 provide estimation results of variants of Equation (14). In column 2, the period effects, which could be correlated with changes in federal policy embodied in regulatory statutes, are removed. The resulting regulation coefficient is nearly identical (-0.0711) and retains its $1 \%$ level of statistical significance, strongly suggesting that unobserved common shocks (which includes common economic conditions) are uncorrelated with the regulation series, as their omission would otherwise bias the regulation coefficient. In column 3, we follow Chambers et al. (2018) and replace the period fixed effects with direct measures of the business cycle. The coefficient on unemployment is positive and statistically significant at the $1 \%$ level,

\footnotetext{
${ }^{5}$ Based on SUSB data, Chambers et al. (2018) reports that 58,938,147 workers were employed by firms with fewer than 500 employees in 2015.
} 
albeit economically insignificant with a coefficient value of 0.0096 . In other words, a one percentage-point increase in the unemployment rate (e.g. an increase from $4 \%$ to $5 \%$ unemployment) reduces the employment share of small firms by just under $0.01 \%$. On the other hand, the GDP Gap turns out to be statistically insignificant. Overall, the magnitude of the estimated regulation coefficient increases slightly (-0.0989), implying that a $1 \%$ increase in federal regulations reduces the employment share of small firms by just over $0.09 \%$. Finally, column 4 eliminates both industry and time period fixed effects. The regulation coefficient is nearly identical to that of column 3 , in which the period fixed effects are replaced by the business cycle covariates. Taken together, these results imply that (i) most of the variation in the employment share panel is cross sectional (not temporal); (ii) omitted variable bias does not appear to be a pressing problem; and (iii) increasing regulation exerts a negative and statistically significant impact on the employment share of small firms.

\subsection{Output Share of Small Firms}

To assess the final implication of our model, namely that greater federal regulations reduce the output share of small firms, we match gross receipts (i.e. output) by industry and firm size from the Census Bureau's SUSB dataset with federal regulations from RegData. Unfortunately, the monetary value of output is only available during Economic Census years (i.e. years ending in 2 or 7), which limits NAICS-based receipt data to three time periods: 2002, 2007 and 2012. Using this short panel, we estimate a log-log fixed effects model very similar to Bailey and Thomas $(2017)^{6}$ :

$$
\text { output }_{\text {it }}=\alpha_{i}+\delta_{t}+\beta \cdot \operatorname{reg}_{i t}+u_{i t}
$$

where output ${ }_{i t}$ is the natural $\log$ of the share of total industry i's output produced by small firms in year $(\mathrm{t}), \alpha_{\mathrm{i}}$ is the industry fixed effect, $\delta_{\mathrm{t}}$ is a period fixed effect, reg $_{i t}$ is the natural $\log$ of total federal regulatory restrictions applicable to industry $i$ in year $t$, and $u_{i t}$ is a mean zero error term. The industry fixed effects capture any differences in average

\footnotetext{
${ }^{6}$ Bailey and Thomas (2017) separately regress the natural log of firm births and deaths onto an industryspecific fixed effect, time period effect, and a one-year lag of the natural log of federal regulations. Because our output panel contains only three time periods which are spaced five years apart, we follow Chambers et al. (2018) and regress our dependent variable on the natural log of contemporaneous regulation.
} 
output shares of small firms across industries, while period fixed effects capture common shocks to output shares across industries. As with Equation (14), the coefficient on industry regulations has an elasticity interpretation. The estimates of Equation (15) are provided in Table 2 .

In our preferred specification (see column 1 of Table 2), the regulation coefficient is negative and statistically significant at the $5 \%$ level, implying that a ten percent increase in federal regulations reduces the output share of small firms by nearly $1.5 \%{ }^{7}$ As with the employment share model, higher regulations appear to benefit large firms at the expense of their smaller competitors. The goodness of fit of this simple model is also quite high, explaining nearly $97 \%$ of the variation in share of small firm output. To verify the robustness of these results, we employ the same estimation strategy used in Section 3.1. As it turns out, the results are similar to those from the employment share model in Section 3.1, namely: (i) most of the variation in the output share panel is cross sectional (not temporal); (ii) our model does not suffer from any omitted variable bias; and (iii) increasing regulation has a negative and statistically significant impact on the output share of small firms.

In column 2, the period effects, which could be correlated with changes in federal policy embodied in regulatory statutes, are removed. The resulting regulation coefficient retains its 5\% level of statistical significance and negative sign, declining slightly in magnitude to -0.0992 . This implies that a ten percent increase in industry-specific federal regulations reduces small firms' share of output by just less than $1 \%$. In column 3 , we replace the period fixed effects with direct measures of the business cycle. Although both business cycle covariates are statistically insignificant, the regulation coefficient is identical in magnitude to our preferred specification in column 1 . This strongly suggests that the period effects are capturing business cycle variations; but given the unchanging goodness of fit across columns 1 to 3 , the business cycle plays no role in driving changes in small firms' output shares over time. Finally, column 4 eliminates both industry and time period fixed effects. The regulation coefficient is nearly identical to that of column 2 , in which the period fixed effects are omitted.

\footnotetext{
${ }^{7}$ Due to the limited number of time periods (3), we cannot estimate robust standard errors clustered by industry. Instead, we report ordinary standard errors.
} 


\section{Conclusion}

Using the two-sector dynamic general equilibrium macroeconomic model developed by Dhawan and Guo (2001), we obtain three empirically testable hypothesis regarding the disparate impact of federal regulations on small and large firms: 1) a reduction in the total number of small firms, 2) the employment share of small firms shrinks, and 3) small firms' share of total output declines. Utilizing the relatively new RegData database, the first of these implications has already been confirmed by Bailey and Thomas (2017) and Chambers et al. (2018), while this paper is the first (to our knowledge) to provide empirical evidence in support of the latter two implications. Specifically, we find that a ten percent increase in federal regulations reduces the employment share of small firms by nearly $0.7 \%$, and an equally large increase in federal regulations (10\%) reduces the output share of small firms by nearly $1.5 \%$. Although these effects may seem small on the margin, these impacts are economically significant vis-à -vis the sheer number of small businesses in the U.S. In addition, each regulation may operate like tossing an individually small pebble into a running stream, the cumulative long-run impact of many pebbles may dam the river. Therefore, when policy makers consider drafting new government regulations, they should exercise caution and carefully weigh any estimated benefits against the costs borne disproportionately by small businesses. 


\section{References}

Bailey, J. B., and D. W. Thomas (2017), "Regulating Away Competition: The Effect of Regulation on Entrepreneurship and Employment," Journal of Regulatory Economics 52, 237-254.

Chambers, D., McLaughlin, P. A., and T. Richards (2018), "Regulation, Entrepreneurship, and Firm Size,” Mercatus Working Paper, April 2018.

Crain, W. M., and N. V. Crain (2014), The Cost of Federal Regulation to the US economy, Manufacturing and Small Business, National Association of Manufacturers, Washington, D.C., September.

Davis, S. J., Haltiwanger, J. C., and S. Schuh (1998), Job Creation and Destruction, MIT Press, Cambridge, MA.

Dawson, J. W. and J. J. Seater (2013), "Federal Regulation and Aggregate Economic Growth,” Journal of Economic Growth 18, 137-177.

Dhawan, R. (1996), Firm Size, Financial Intermediation and Business Cycles, Commonwealth Publishers, New Delhi, India.

Dhawan, R. and J.-T. Guo (2001), "Declining Share of Small Firms in U.S. Output: Causes and Consequences," Economic Inquiry 39, 651-662.

Feigenbaum, A. and A. Karnani (1991), "Output Flexibility -- A Competitive Advantage For Small Firms," Strategic Management Journal, 12, 101-114.

Goldschlag, N., and A. Tabarrok (2018), "Is Regulation to Blame for the Decline in American Entrepreneurship?" Economic Policy 33, 5-44.

Kitching, J., Hart, M. and N. Wilson (2015), "Burden or Benefit? Regulation as a Dynamic Influence on Small Business Performance," International Small Business Journal 33, 130-147.

McLaughlin, P. A., and O. Sherouse (2017), "QuantGov - A Policy Analytics Platform." Working paper, Dec. 20, http://docs.quantgov.org/quantgov_working_paper.pdf.

Mills, D. and L. Schumann (1985), "Industry Structure with Fluctuating Demand," American Economic Review 75, 758-767. 
Table 1 - Employment Share Panel Estimates

\begin{tabular}{|c|c|c|c|c|}
\hline Variables & (1) & (2) & (3) & (4) \\
\hline \multirow[t]{2}{*}{ Log Regulations (lagged) } & $-0.0705^{* * *}$ & $-0.0711 * * *$ & $-0.0989 * * *$ & $-0.1030 * * *$ \\
\hline & $(0.0176)$ & $(0.0269)$ & $(0.0208)$ & $(0.0049)$ \\
\hline \multirow[t]{2}{*}{ Unemployment } & --- & --- & $0.0096 * * *$ & --- \\
\hline & & & $(0.0012)$ & \\
\hline \multirow[t]{2}{*}{ GDP Gap } & --- & --- & 0.0042 & --- \\
\hline & & & $(0.0040)$ & \\
\hline Industry Fixed Effects? & Yes & Yes & Yes & No \\
\hline Time Period Fixed Effects? & Yes & No & No & No \\
\hline Observations & 3,598 & 3,598 & 3,598 & 3,598 \\
\hline Goodness of Fit & 0.961 & 0.960 & 0.960 & 0.024 \\
\hline \multicolumn{5}{|c|}{ Notes: 1) Dependent variable is the natural log of the share of total 5-digit } \\
\hline \multicolumn{5}{|c|}{ NAICS industry output produced by small firms in a given year } \\
\hline \multicolumn{5}{|c|}{ 2) Intercept included by not reported } \\
\hline \multicolumn{5}{|c|}{ 3) White robust standard errors clustered by industry in parenthesis } \\
\hline \multicolumn{5}{|c|}{ 4) $* * *, * *$, and $*$ denote $1 \%, 5 \%$, and $10 \%$ statistical significance } \\
\hline
\end{tabular}


Table 2 - Output Share Panel Estimates

\begin{tabular}{|c|c|c|c|c|}
\hline Variables & (1) & (2) & (3) & (4) \\
\hline \multirow[t]{2}{*}{ Log Regulations } & $-0.1494 * *$ & $-0.0992 * *$ & $-0.1494 * *$ & $-0.0966 * * *$ \\
\hline & $(0.0675)$ & $(0.0443)$ & $(0.0675)$ & $(0.0277)$ \\
\hline \multirow[t]{2}{*}{ Unemployment } & --- & --- & 0.0096 & --- \\
\hline & & & $(0.0095)$ & \\
\hline \multirow[t]{2}{*}{ GDP Gap } & --- & --- & 0.0065 & --- \\
\hline & & & $(0.0093)$ & \\
\hline Industry Fixed Effects? & Yes & Yes & Yes & No \\
\hline Time Period Fixed Effects? & Yes & No & No & No \\
\hline Observations & 561 & 561 & 561 & 561 \\
\hline Goodness of Fit & 0.968 & 0.968 & 0.968 & 0.021 \\
\hline \multicolumn{5}{|c|}{ Notes: 1) Dependent variable is the natural log of the share of total 5-digit } \\
\hline \multicolumn{5}{|c|}{ NAICS industry output produced by small firms in a given year } \\
\hline \multicolumn{5}{|c|}{ 2) Intercept included by not reported } \\
\hline \multicolumn{5}{|c|}{ 3) Standard errors in parenthesis } \\
\hline \multicolumn{5}{|c|}{ 4) $* * *, * *$, and $*$ denote $1 \%, 5 \%$, and $10 \%$ statistical significance } \\
\hline
\end{tabular}

